\title{
PLGA nanoparticles delivering CPT-11 combined with focused ultrasound inhibit platinum resistant ovarian cancer
}

\author{
Xiaogang Zhu ${ }^{1}$, Siqi Yan $^{2,3}$, Fang Xiao ${ }^{1}$, Min Xue $^{1}$ \\ ${ }^{1}$ Department of Gynecology, Third Xiangya Hospital, Central South University, Changsha, China; ${ }^{2}$ Department of Oncology, Second Xiangya \\ Hospital, Central South University, Changsha, China; ${ }^{3}$ Department of Radiation Oncology, Hunan Academy of Traditional Chinese Medicine \\ Affiliated Hospital, Changsha, China \\ Contributions: (I) Conception and design: X Zhu, M Xue; (II) Administrative support: M Xue; (III) Provision of study materials or patients: X Zhu, \\ S Yan; (IV) Collection and assembly of data: S Yan, F Xiao; (V) Data analysis and interpretation: F Xiao; (VI) Manuscript writing: All authors; (VII) \\ Final approval of manuscript: All authors. \\ Correspondence to: Min Xue, MD. Department of Gynecology, the Third Xiangya Hospital of Central South University,138 Tongzipo Rd. Changsha \\ 410013, China. Email: xuemin1234@126.com.
}

Background: Ovarian cancer cells show resistance to platinum drugs treatment, which brings a big challenge to clinical therapeutics. This study aimed to construct effective drug delivering nanoparticles specifically targeting ovarian cancer cell.

Methods: Poly lactic-co-glycolic acid (PLGA) were used to form Nano-spheres by double emulsion method, and to deliver CPT-11. Connected with targeted LHRH-a molecules, their effects were tested by ovarian cancer cell A2780/DDP in vitro and in vivo.

Results: We successfully constructed PLGA nanoparticles carrying LHRH-a (Luteinizing hormone releasing hormone analogue) and CPT-11 (irinotecan $\mathrm{HCl}$ trihydrate), which can specifically target LHRH receptor high expression ovarian cancer cell A2780/DDP (cisplatin). Combined with focused ultrasound in vitro, LHRH-a/CPT-11/PLGA nanoparticles significantly inhibited the proliferation of A2780/DDP cells (a cisplatin-resistant A2780 cell line), and the cells were obviously arrested at S phase. Both the mRNA expression and protein level of Caspase 3 increased, while Bcl-2 and MMP2 declined, which promoted apoptosis. In vivo, LHRH-a/CPT-11/PLGA nanoparticles bind specifically with LHRH receptor on xenograft tumors of A2780/DDP. With focused ultrasound, LHRH-a/CPT-11/PLGA nanoparticles inhibited the growth of A2780/DDP xenograft tumors significantly. The expression level of VEGF, Bcl-2 and MMP2 reduced, while Caspase 3 increased in tumors.

Conclusions: CPT-11 delivering PLGA nanoparticles with LHRH-a specifically target ovarian cancer cell A2780/DDP, and work locally when combined with focused ultrasound. They increase local drug concentration and reduce side effects. This research may provide a new effective therapeutic strategy for recurrent platinum resistant ovarian cancer.

Keywords: Poly lactic-co-glycolic acid nanoparticles (PLGA nanoparticles); focused ultrasound; ovarian cancer; cell cycle arrest; apoptosis

Submitted Oct 29, 2020. Accepted for publication Feb 22, 2021.

doi: $10.21037 /$ tcr-20-3171

View this article at: http://dx.doi.org/10.21037/tcr-20-3171 


\section{Introduction}

Ovarian cancer (OC) is the most common malignant tumor of gynecology. According to the latest statistics, ovarian cancer accounted for $22.9 \%$ of reproductive tract cancer (1). Around $80 \%$ OC cases have already developed to middle or late stages when diagnosed. Therefore, the mortality rate ranks first in gynecological cancers (2). Clinically, platinum drugs (cisplatin, carboplatin, oxaliplatin, nedaplatin, etc.) combined with paclitaxel is the first-line chemotherapy regimen for ovarian cancer. However, $70 \%$ patient relapse after initial treatment and show resistance to platinum drugs, which is the main cause of patients' death (3). For those platinum-resistant patients with recurrent $\mathrm{OC}$, the second-line chemotherapy without cross-resistance with platinum is necessary. The commonly used drugs including camptosar (CPT-11), while those drugs have limit effects and severe side effects (4). CPT-11, a semi-synthetic derivative of camptoacine, is a selective inhibitor of DNA topoisomerase I (Topo I). However, the efficacy of CPT-11 is not high. ten Bokkel Huinink et al. found that the total response rate of CPT-11 for recurrent OC was only $20-25 \%$ (5). In the phase II clinical study of Takeuchi et al. (6), 52 OC patients who had received chemotherapy were treated with CPT-11, and they also found that the response rate was $23 \%$. In addition, CPT- 11 had obvious adverse reactions, e.g., delayed diarrhea and neutropenia (7). After CPT-11 administration, more than $40 \%$ patients exhibited III-IV degree of diarrhea, $78.7 \%$ patients showed neutropenia, and the incidence of IIIIV neutropenia up to $48 \%$ (8). Because of the serious side effects, the treatment has to be stopped in advance or the doses has to be reduced (9), and that's one of the key factors which limit its dosage and effectiveness.

Macromolecular polymers have the property of forming capsule and film, with a very good stability. The surface of drug-carrying microsphere can be coupled with antibodies or ligands after appropriate treatment (10). It is known that OC cells specifically express the luteinizing hormonereleasing hormone (LHRH) receptors (11). Platinumresistant A2780/DDP cells of OC highly express LHRH receptor, and lipid microspheres carrying paclitaxel (PTX) linked with LHRH-a through biotin can accurately deliver drugs to the target area (12). Poly lactic-co-glycolic acid (PLGA) microsphere is a new kind of polymer drugcarrying microsphere. Compared with lipid microspheres, PLGA microsphere has obvious advantages, including the small particle size, higher loading rate, ability to be complete depredated into non-toxic $\mathrm{H}_{2} \mathrm{O}$ and $\mathrm{CO}_{2}$ in human body, and satisfactory stability (10). Generally, the maximum size of tumor vascular endothelial space is up to $800 \mathrm{~nm}$ (13), and PLGA microsphere can be made into nanometer particles with $10-500 \mathrm{~nm}$ size, which is easy to reach the target through the vascular endothelial space.

Luteinizing hormone releasing hormone analog (LHRH-a) is an ideal peptide molecule targeting OC cells, and A2780/DDP express LHRHR (Luteinizing hormone releasing-hormone receptor) is an ideal cell line for the study of platinum-resistant OC.

In this study, PLGA nanoparticles were loaded with CPT-11 and LHRH-a, which increased the targeting of nanoparticles and their drugs to OC cells, a novel CPT11 loaded nanoparticles was successfully synthesized with PLGA material and it was connected with LHRH-a molecules. This novel targeted drug-loaded nanoparticle (LHRH-a/CPT-11/PLGA) can specifically bind to OC cells and locally release CPT-11 when triggered by focused ultrasound irradiation. Theoretically, this strategy can improve the overall treatment efficacy and our study provides a reference for the further treatment of recurrent platinum-resistant OC.

We present the following article in accordance with the ARRIVE reporting checklist (available at http://dx.doi. org/10.21037/tcr-20-3171).

\section{Methods}

\section{Materials}

Human OC cell line A2780/DDP was purchased from Shanghai Suer Biotechnology Co., Ltd. RPMI 1640 culture medium (containing $10 \%$ fetal bovine serum) was used to culture the cells at $37{ }^{\circ} \mathrm{C}$ and with $5 \% \mathrm{CO}_{2}, 10 \%$ fetal bovine blood should be added before use, penicillin and streptomycin were added (final concentrations of 100 and $100 \mathrm{U} / \mathrm{mL}$, respectively). The study was conducted in accordance with the Declaration of Helsinki (as revised in 2013).

\section{Preparation of PLGA nanospheres}

PLGA- $\mathrm{H}_{2} \mathrm{O}$ nanoparticles were prepared by double emulsion method: $25 \mathrm{mg}$ PLGA was dissolved in $2 \mathrm{~mL}$ trichloromethane, and then $0.2 \mathrm{~mL}$ double distilled water was added to the solution. The white emulsion (w/o nanometer microsphere) was obtained by oscillating the 
continuous wave $45 \mathrm{~s}$ with an energy of $80 \mathrm{w}$. Next, $2.5 \mathrm{~mL}$ $5 \%$ of PVA was added, and the high-speed dispersing homogenizer was used (1,300 r/min for $2 \mathrm{~min})$. The $\mathrm{w} / \mathrm{o} / \mathrm{w}$ microspheres were generated. Then, it was stirred for $2 \mathrm{~h}$ to fully volatilize trichloromethane at room temperature with the magnetic mixer. After high-speed centrifugal washing for 3-5 times (5,000 rpm for $5 \mathrm{~min}$ ) by $\mathrm{ddH}_{2} \mathrm{O}, \mathrm{PLGA}-\mathrm{H}_{2} \mathrm{O}$ nanoparticles were collected and stored at $4{ }^{\circ} \mathrm{C}$ until use.

Preparation of CPT-11/PLGA nanospheres: $1 \mathrm{mg}$ CPT11 powder was added into $0.2 \mathrm{~mL}$ deionized water to produce the $5.0 \mathrm{mg} / \mathrm{mL}$ CPT- 11 solution, and then it was added to chloroform solution with PLGA.

Preparation of targeted nanospheres (LHRH-a/CPT-11/ PLGA): the targeted nanospheres were prepared through the method of double emulsification and carbodiimide activation. The CPT-11/PLGA microspheres were dissolved in MES Buffer solution ( $\mathrm{pH}=6$ ), and the activators EDC and INHS were added according to the mass ratio of 1:2:2. Then $2 \mathrm{mg}$ LHRH-a were added into the solution, mixed at $4{ }^{\circ} \mathrm{C}$ on shaker for 3 hours. The liquid system was centrifuged at 5,000 rpm and washed for 3-5 times with the MES buffer solution $(\mathrm{pH}=8)$.

FITC-labeled CPT-11/PLGA nanospheres: these microspheres were prepared by the method of double emulsification. On the basis of CPT-11/PLGA nanospheres, an appropriate amount of FITC. Fluorescent marker dye was added at the same time.

FITC-labeled targeted nanospheres (FITC-LHRH-a/ CPT-11/PLGA): on the basis of LHRH-a/CPT-11/PLGA microspheres, an appropriate amount of FITC-fluorescent marker dye was added into the solution at the same time.

All the above microspheres were sterilized by Co60 irradiation sterilization (25 Gy). The irradiation site was the radiation center of the third military medical university. Microspheres after sterilization were stored at $-20{ }^{\circ} \mathrm{C}$ for later use.

\section{Encapsulation rate and drug loading rate assessment}

The maximum absorption wavelength of CPT-11 was determined. The CPT-11 solution was $(20 \mu \mathrm{g} / \mathrm{mL})$ was conducted ultraviolet scanning at $200-600 \mathrm{~mm}$. Next, $25 \mu \mathrm{L}$ LHRH-a/CPT-11/PLGA nanospheres suspension was diluted to a volume of $250 \mu \mathrm{L}$ and placed in a $37{ }^{\circ} \mathrm{C}$ gas bath oscillator. After full degradation, the solution was centrifuged at $500 \mathrm{rpm}$ for $10 \mathrm{~min}$, the absorbance value was determined at the wavelength of $254.5 \mathrm{~nm}$ and $500 \mathrm{~mm}$ with an ultraviolet spectrophotometer. In LHRH-a/CPT-
11/PLGA nanospheres, the CPT-11 content was calculated as: the determined concentration $\times$ solvent volume $(250 \mu \mathrm{L})$. The drug loading (\%) was calculated as: CPT-11 content/total weight of nanospheres $\times 100 \%$. Encapsulation rate (\%) was calculated as: CPT-11 content in nanospheres/ total drug input $\times 100 \%$. The experiment was repeated three times and the averaged results were used for analysis.

\section{Cell viability assays}

The cell concentration was adjusted to $1 \times 10^{5} / \mathrm{mL}$ and inoculated on a 96-well plate with $100 \mu \mathrm{L}$ per well. The cells were cultured overnight in an incubator. Different concentrations of CPT-11 were added into the cells and then cultured in incubator for 24, 48 and $72 \mathrm{~h}$. Next, $10 \mu \mathrm{L}$ CCK-8 solution was added to each well and incubated for $4 \mathrm{~h}$, and then the absorbance value at $450 \mathrm{~mm}$ was determined. Besides, the half inhibitory concentration (IC50) was calculated based on the cell viability.

\section{In vitro targeting detection assays}

Routine trypsin digestion and cell counting were performed on A2780/DDP cells during the logarithmic growth period, and the cells were divided into three groups: (I) the fluorescence targeted microspheres group (FITC-labeled LHRH-a/CPT-11/PLGA microspheres); (II) the pretreatment fluorescence targeted microsphere group (LHRH-a pretreated and FITC-labeled LHRH-a/ CPT-11/PLGA microsphere); (III) fluorescence nontargeted microspheres group (the FITC-labeled CPT11/PLGA microspheres). The cells in the three groups were respectively treated with $40 \%$ paraformaldehyde and fixed for $15 \mathrm{~min}$ and were washed with PBS for three times. The nuclei were stained with DAPI (PBS diluted, 1:1,000) for $3 \mathrm{~min}$. The slices were sealed with glycerin. The fluorescence distribution was detected with a confocal microscope.

\section{Cell cycle assays}

The cells were cultured in 6-well plates, and when the density in a plate reached $60-70 \%$, the corresponding drugs, reagents and microspheres were added respectively (the same amount of normal saline was added in the control group). The ultrasonic irradiation group was treated with ultrasonic intensity irradiation of $1.5 \mathrm{~W} / \mathrm{cm}^{2}$ for $60 \mathrm{~s}$. After treatment, cells were collected, $1 \mathrm{~mL}$ pre-cool $70 \%$ 
ethanol was added to cells, gently blown and mixed, and then fixed at $4{ }^{\circ} \mathrm{C}$ for $2 \mathrm{~h}$. Subsequently, $0.5 \mathrm{~mL}$ propidium iodide staining solution $(0.5 \mathrm{~mL}$ staining buffer, containing $25 \mu \mathrm{L} 20 \times$ propidium iodide staining solution and $10 \mu \mathrm{L}$ $50 \times$ RNase A) was added, cells were re-suspended and incubated for $30 \mathrm{~min}$ at $37^{\circ} \mathrm{C}$ in dark. The fluorescence at $488 \mathrm{~nm}$ wavelength was detected by flow cytometry. The experiment was independently repeated three times.

\section{Western blotting}

Cells were lysed in lysis buffer (Biyuntian, CHINA). After being determined the protein concentration, the cellular protein was subjected to SDS-PAGE and western blot analysis with the following primary antibodies. Bcl2, Caspase3, MMP2, GAPDH antibody was bought from Abcam HA.

\section{$R N A$ extraction and QPCR assays}

After the culture medium was discarded, TRIzol reagent was directly added to the culture plate for RNA extraction. And reverse transcription was performed. The primers used for RT-PCR were as follows (5'-3'): Bcl-2: AGGGACGGGGTGAACTGG; CTACCCAGCCTCCGTTATCC. Casp3: AGAACT G G A C T G T G G C A T T G A G ; G G C A C A AAGCGACTGGATG. MMP2: TTTGAC G G TA A G G A C G G A C T C ; TA C T C C C C ATCGGCGTTC. Actin: TGACGTGGACATC CGCAAAG; CTGGAAGGTGGACAGCGAGG.

\section{In vivo tumor studies}

The animal experiment was approved by the Ethics Committee of The IRB of Third Xiangya Hospital, Central South University. BAL B/C female nude mice ( 5 weeks old, $20 \mathrm{~g}$ ) were purchased from Beijing Huafukang Biological Technology Co., Ltd. The animals were kept in a SPF room, and all the materials for breeding were strictly sterilized. Experiments were performed under a project license (license number: 2020SYDW0627) granted by the Veterinäramt des Kantons Zürich, Switzerland, in compliance with the Swiss Animal Protection Act (TSchG) and the Swiss Animal Protection Ordinance (TSchV).

Construction of subcutaneous transplantation tumor was performed on nude mice as follow. A2780/DDP cells in logarithmic growth stage were prepared into cell suspension with concentration of $1 \times 10^{7} / \mathrm{mL}$ after routine digestion and centrifugation. Around $1.5 \times 10^{6}$ tumor cells were transplanted subcutaneously in each nude mouse. Subsequent experiment grouping was: blank control group (Con); CPT-11 group (CPT-11); CPT-11 combined ultrasound group (CPT-11 and US); PLGA- $\mathrm{H}_{2} \mathrm{O}$ microsphere group (PLGA- $\mathrm{H}_{2} \mathrm{O}$ ); $\mathrm{PLGA}_{-} \mathrm{H}_{2} \mathrm{O}$ microsphere combined ultrasound group (PLGA- $\mathrm{H}_{2} \mathrm{O}$ and US); CPT11/PLGA microsphere group (CPT-11/PLGA); CPT-11/ PLGA microsphere combined ultrasound group (CPT11/ PLGA and US); LHRH-a/CPT-11/PLGA microsphere group (LHRH-a/CPT-11/PLGA).

LHRH-a/CPT-11/PLGA microsphere combined ultrasound group (LHRH-a/CPT-11/PLGA and US). After the tumor grew to $0.8-1.0 \mathrm{~cm}, 45$ nude mice with similar tumor size were selected and randomly divided into nine groups (5 nude mice in each group). All groups were treated every 2 days (on 4, 7, 10 and 13 days, respectively). And the tumor volume of nude mice was continuously measured. The tumor inhibition rate was calculated as: (the average tumor weight of control group - the average tumor weight of each treatment group)/the average tumor weight of control group $\times 100 \%$. After nude mice were sacrificed, each tumor was removed, fixed overnight, embedded, and cut into sections for subsequent immune-histochemical experiments.

\section{Statistical analysis}

One-way ANOVA was used to evaluate the difference between the groups. Unpaired Student's $t$-test was used to evaluate the difference between the two groups. $\mathrm{P}<0.05$ was statistically significant, and $\mathrm{P}<0.01$ was extremely statistically significant. Statistical analyses were performed by SYSTAT SigmaPlot 10.0 statistics software.

\section{Results}

\section{LHRH-a/CPT-11/PLGA nanoparticles}

Well-constructed drug-loaded PLGA nanospheres (LHRH-a/CPT-11/PLGA) dissolved in water were milky white suspension. Under the light microscope, they had uniform size, regular morphology, spherical shape and good dispersion, and no obvious adhesion or local agglomeration among the nanoscale microspheres were observed (Figure 1A). Transmission electron microscopy showed that CPT-11 was evenly distributed in the center of PLGA 
A

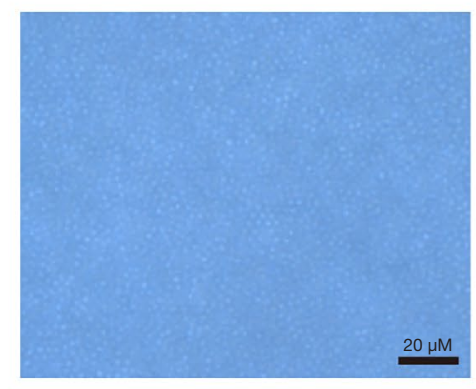

B

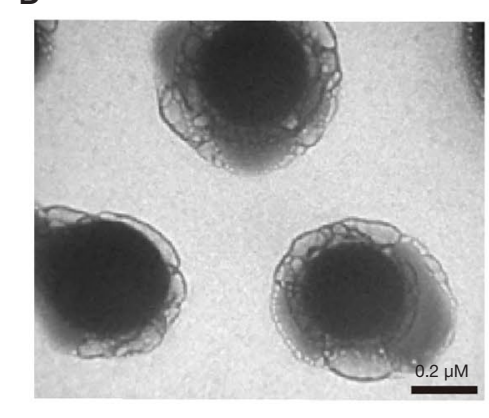

C

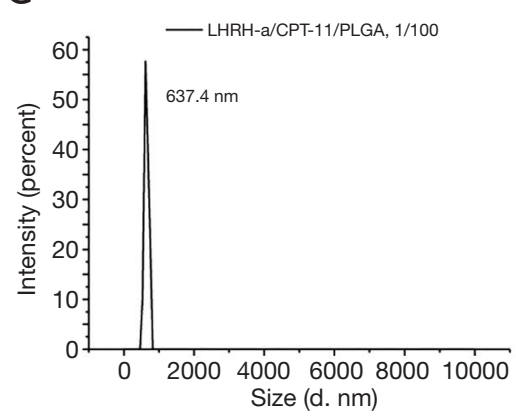

D

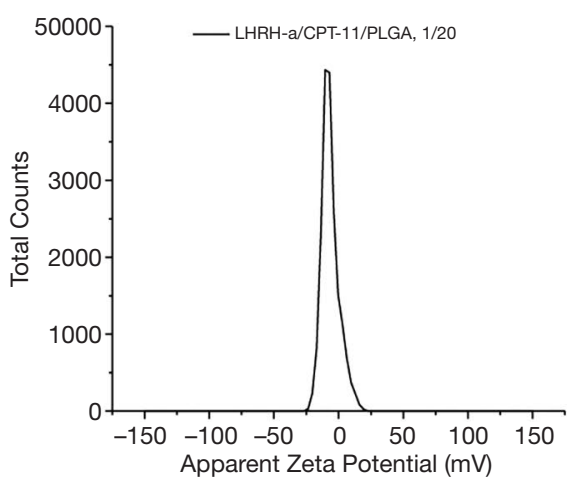

E

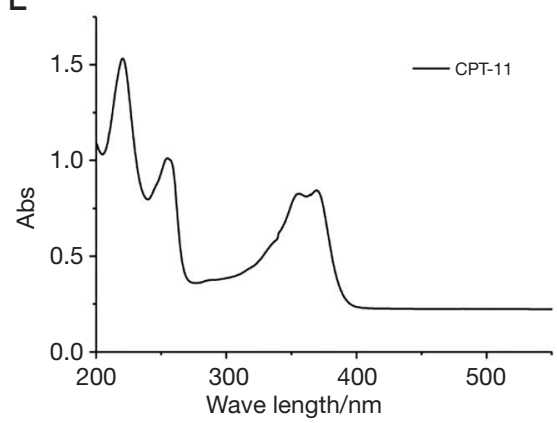

$\mathrm{F}$

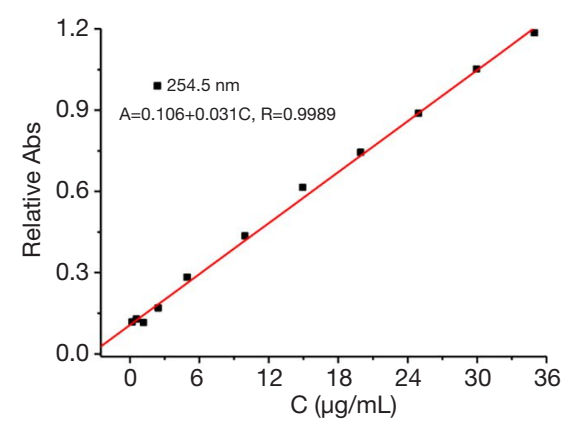

Figure 1 Characteristics of LHRH-a/CPT-11/PLGA nanometer microspheres. (A) LHRH-a/CPT-11/PLGA nanospheres under microscope (×600). (B) Transmission Electron Microscope detection. (C) Particle size distribution of LHRH-a/CPT-11/PLGA. (D) Potential distribution of LHRH-a/CPT-11/PLGA. (E) UV (ultraviolet) scanning spectrum of CPT-11. (F) Calibration curve of CPT-11. LHRH-a, luteinizing hormone releasing hormone analogue; CPT-11, irinotecan $\mathrm{HCl}$ trihydrate; PLGA, poly lactic-co-glycolic acid.

nanometer microsphere (Figure 1B).

The particle size was $637.4 \pm 57.0 \mathrm{~nm}$ (Figure 1C). LHRH-a/CPT-11/PLGA nanometer microspheres were negatively charged, and the ZETA potential after dilution of 20 times was $-6.48 \pm 6.71 \mathrm{mV}$ (Figure $1 D$ ). The UV scanning spectrum of CPT-11 was shown in Figure 1E. CPT-11 has the maximum absorption peak at $254.5 \mathrm{~nm}$, which was used as the measuring wavelength. The regression equation of the content determined of CPT-11 was $\mathrm{A}=0.106+0.031 \mathrm{C}$, $\mathrm{R}=0.9989$ (Figure $1 F)$. There was a linear relationship in the range of $0.250-35.0 \mu \mathrm{g} / \mathrm{mL}$. The encapsulation rate of LHRH-a/CPT-11/PLGA nanometer microsphere was $33.61 \% \pm 8.16 \%$ and the drug load was $4.80 \% \pm 8.16 \%$.

After ray sterilization, there was no significant change in the concentration and morphology of targeted drug-loaded nanospheres (LHRH-a/CPT-11/PLGA). After place at $-20{ }^{\circ} \mathrm{C}$ or $4{ }^{\circ} \mathrm{C}$ for 14 days, their morphology and particle size did not change significantly. However, the particle size of the nanometer microspheres gradually increased with the storage time, and the clustering phenomenon of microspheres appeared after one month (not shown).

\section{Targeted nanoparticles inbibited the proliferation of $O C$ cells}

In vitro, with the increase of CPT-11 concentration, the inhibition rate to A2780/DDP cells increased. Also, the inhibition rate at the same drug concentration showed a time effect. From 24 h, 48 h to 72 h, the inhibition rate of CPT-11 on A2780/DDP cells increased gradually (Figure $2 A$ ), and the $\mathrm{IC}_{50}$ value at $72 \mathrm{~h}$ was $0.2 \mathrm{mg} / \mathrm{mL}$.

Laser confocal microscopy showed the distribution of targeted drug-carrying microspheres with green ring fluorescence around the A2780/DDP cells. After repeated washing with PBS buffer following pretreatment with LHRH-a, little green fluorescence was observed around A2780/DDP cells in the targeted microsphere group (Figure 2B). CPT-11 nanoparticles significantly inhibited 
A

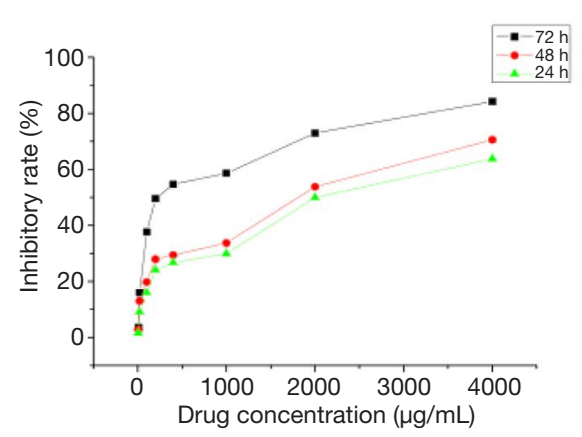

B

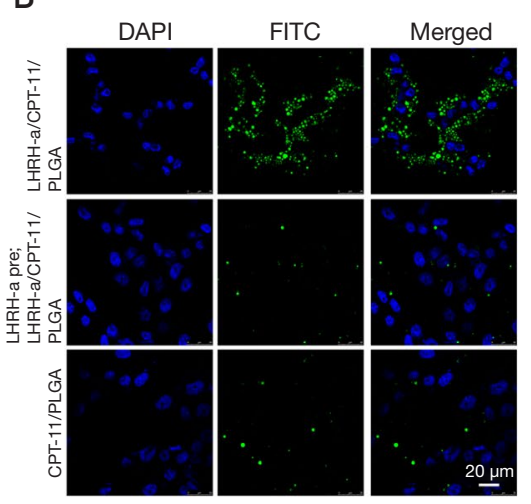

C

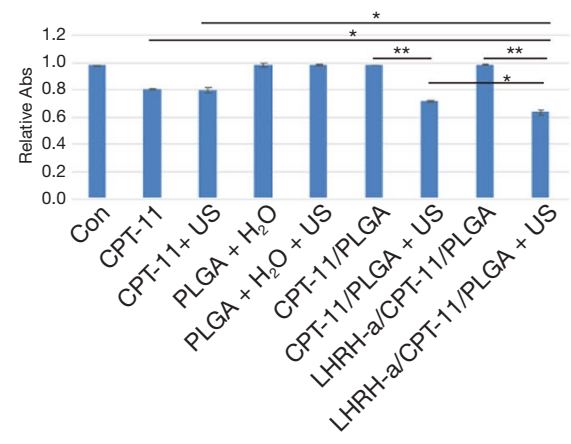

Figure 2 Targeted inhibition of tumor cell proliferation by LHRH-a/CPT-11/PLGA nanometer microspheres. (A) CPT-11 inhibit the proliferation of ovarian cancer cell A2780/DDP (a cisplatin-resistant A2780 cell line). (B) LHRH-a/CPT-11/PLGA target A2780/DDP cells. (C) inhibition effects of treatments on proliferation of A2780/DDP cells. LHRH-a, luteinizing hormone releasing hormone analogue; CPT-11, irinotecan HCl trihydrate; PLGA, poly lactic-co-glycolic acid. *, $\mathrm{P}<0.05$; ** $\mathrm{P}<0.01$.

the proliferation of OC cells. As shown in Figure 2C, there were significant cytotoxic effects on A2780/DDP cells in CPT-11 group, CPT-11 with US group, CPT-11/PLGA with US group and LHRH-a/CPT-11/PLGA with US group. Among them, the cytotoxic effect of LHRH-a/CPT11/PLGA + US group was significantly stronger than that of CPT-11 group ( $\mathrm{P}=0.003)$, CPT-11 with US group $(\mathrm{P}=0.004)$ and CPT-11/PLGA with US group $(\mathrm{P}=0.042)$. The differences between CPT-11/PLGA with US group and CPT-11/PLGA group $(\mathrm{P}=0.001)$, and between LHRH-a/ CPT-11/PLGA with US group and LHRH-a/CPT-11PLGA Group $(\mathrm{P}=0.001)$ were statistically significant. Compared with the control group, there were no significant difference between the pure PLGA- $\mathrm{H}_{2} \mathrm{O}$ group ( $\left.\mathrm{P}=0.957\right)$, the PLGA- $\mathrm{H}_{2} \mathrm{O}$-US group ( $\mathrm{P}=0.837$ ), the CPT-11/PLGA group $(\mathrm{P}=0.671)$, and the LHRH-a/CPT-11/PLGA group $(\mathrm{P}=0.322)$.

Cell cycle distribution was detected by flow cytometry. Compared with the control group (Con), all the A2780/ DDP cells in the showed increased s-phase cell ratio to different degrees, including CPT-11 group $(\mathrm{P}=0.0002)$, CPT-11 with US group ( $\mathrm{P}=0.0002)$, CPT-11/PLGA with US group ( $\mathrm{P}=0.000)$, LHRH-a/CPT-11-PLGA with US group $(\mathrm{P}=0.000)$. The $\mathrm{S}$ phase of cell cycle blocking effect was the strongest in the LHRH-a/CPT-11/PLGA with US group (Figure $3 A$ ).

We have preliminarily demonstrated that targeted drugcarrying microspheres combined with focused ultrasound can strongly inhibit the proliferation of tumor cells. In the follow-up experiments, we further detected the expression of proteins related to apoptosis and invasion of OC cells after treatment of targeted drug-carrying microspheres combined with focused ultrasound. The mRNA expression level of Caspase3 in LHRH-a/CPT-11/PLGA with US group was significantly up-regulated, and the expression levels of Bcl-2 and MMP2 in this group were lower than other groups. AS shown in Figure 3B, the mRNA expression of Bcl-2, Caspase3 and MMP2 in LHRH-a/ CPT-11/PLGA-US group was significantly different from that of other treatment groups $(\mathrm{P}<0.01)$. While the differences between the PLGA- $\mathrm{H}_{2} \mathrm{O}$ group, PLGA- $\mathrm{H}_{2} \mathrm{O}$ with US group, CPT-11/PLGA group and LHRH-a/ CPT-11/PLGA group were not statistically significant versus control $(\mathrm{P}>0.05)$. The levels of $\mathrm{Bcl}-2$, Caspase 3 and MMP2 protein expression were significantly changed in all treatment groups. And the expressions of Bcl-2, Caspases3 and MMP2 in the LHRH-a/CPT11/PLGA with US group were significantly higher than those in the other treatment groups $(\mathrm{P}<0.05)$, while the expression levels of $\mathrm{Bcl}-2$ and MMP2 in the LHRH-a/CPT11/PLGA + US group were significantly lower than those in the other groups $(\mathrm{P}<0.05)$. There was no significant difference between the simple PLGA- $\mathrm{H}_{2} \mathrm{O}$ group, the PLGA- $\mathrm{H}_{2} \mathrm{O}$ with US group, the CPT-11/PLGA group, the LHRH-a/CPT-11/PLGA group and the control group $(\mathrm{P}>0.05)$ (Figure $3 \mathrm{C}, \mathrm{D})$.

\section{Nanoparticles inbibit the growth of OC cells in vivo}

In order to verify whether these microspheres can inhibit targeted tumor in vivo, we established the subcutaneous 

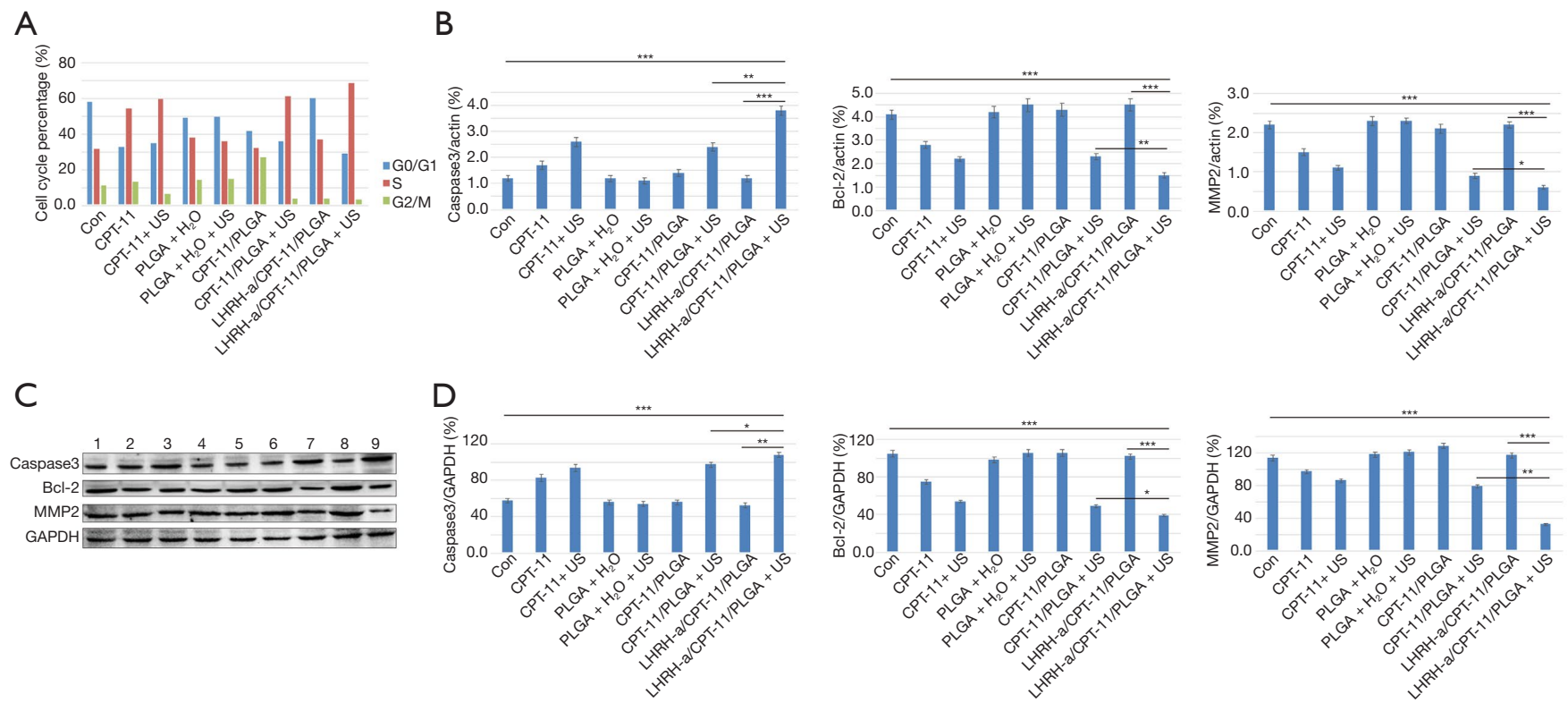

Figure 3 LHRH-a/CPT-11/PLGA nanometer microspheres promote apoptosis of ovarian cancer cells. (A) Cell phase distribution of A2780/DDP cells (a cisplatin-resistant A2780 cell line) in the treatment by FCM (Flow cytometry). (B) mRNA level of Bcl-2/caspase3, and MMP2. (C,D) Protein level of Bcl-2/caspase3, and MMP2. In Figure 3C, 1, 2, 3, 4, 5, 6, 7, 8 and 9 represent Con, CPT-11, CPT-11 + US (focused ultrasound), PLGA + $\mathrm{H}_{2} \mathrm{O}$, PLGA + $\mathrm{H}_{2} \mathrm{O}+\mathrm{US}$, CPT-11/PLGA, CPT-11/PLGA + US, LHRH- $\alpha /$ CPT-11/PLGA, LHRH- $\alpha /$ CPT-11/PLGA + US. LHRH-a, luteinizing hormone releasing hormone analogue; CPT-11, irinotecan HCl trihydrate; PLGA, poly lacticco-glycolic acid. *, $\mathrm{P}<0.05 ;{ }^{* *}, \mathrm{P}<0.01 ;{ }^{* * *}, \mathrm{P}<0.001$.

transplantation tumor model Using the nude mice (Figure 4A), and the nanoparticle therapy was administered when tumors formed. Under the confocal laser microscope, there was a large amount of green fluorescence distribution around cells in the fluorescence targeted microspheres group after injection of FITC-labeled LHRH-a/CPT-11/ PLGA microspheres (Figure 4B). However, no significant green fluorescence was observed in the tumor tissues of the LHRH-a pretreated group and the non-targeted fluorescent microsphere group.

As tumor growth curve shown in Figure $4 C$, the tumor growth of the control group, PLGA- $\mathrm{H}_{2} \mathrm{O}$ group, PLGA$\mathrm{H}_{2} \mathrm{O}$ with US group, CPT-11/PLGA group and LHRH-a/ CPT-11/PLGA group was rapider than other treatment groups. The tumor growth of the LHRH-a/CPT-11/PLGA with US group was the slowest, and the tumor volume was significantly smaller than that of the other groups. There was no significant difference in growth inhibition among the PLGA- $\mathrm{H}_{2} \mathrm{O}$ group, PLGA- $\mathrm{H}_{2} \mathrm{O}$ with US group, CPT11/PLGA group and LHRH-a/CPT-11/PLGA group in comparison with the control group $(\mathrm{P}=0.05)$.

Different degrees of tumor growth inhibition were observed in the CPT-11 with the US group, CPT-11/ PLGA with US group and LHRH-a/CPT-11/PLGA with US group compared with the control group. Among them, the LHRH-a/CPT-11/PLGA with US group had the strongest inhibition effect $(\mathrm{P}=0.025)$, as shown in Figure $4 D$. After sacrifice, the weight of the dissected tumor was compared, the LHRH-a/CPT-11/PLGA with US group had the lowest weight (inhibition rate $73.5 \%$ ). Above findings suggest that the targeted microspheres combined with focused ultrasound could achieve $g$ inhibition of tumor growth than the single drug treatment.

From this experiment, we found that targeting drugdelivering microsphere joint focused ultrasound irradiation group of nude mice subcutaneous transplantation tumor growth inhibition is the strongest. While tumor inhibition rate of the blank control group, PLGA- $\mathrm{H}_{2} \mathrm{O}$ group, PLGA$\mathrm{H}_{2} \mathrm{O}$ with US, CPT-11/PLGA group and LHRH-a/ CPT-11 were low and without statistical difference between groups. Firstly, PLGA- $\mathrm{H}_{2} \mathrm{O}$ and PLGA- $\mathrm{H}_{2} \mathrm{O}$ joint of ultrasonic irradiation had no obvious inhibition effect on tumor; secondly, inhibition of CPT-11/PLGA and LHRH-a/CPT-11/PLGA on tumor tissue had no 
A
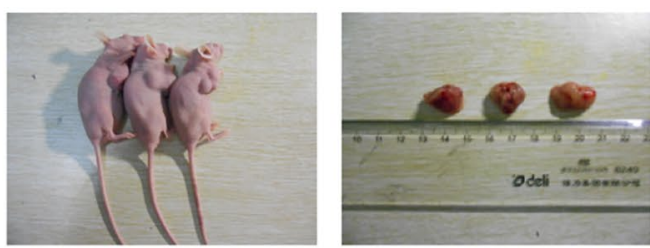

B

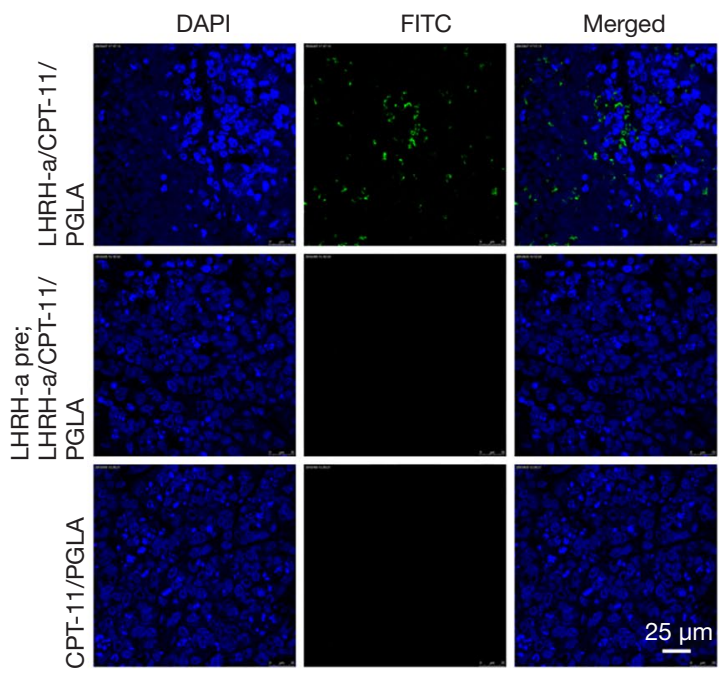

C

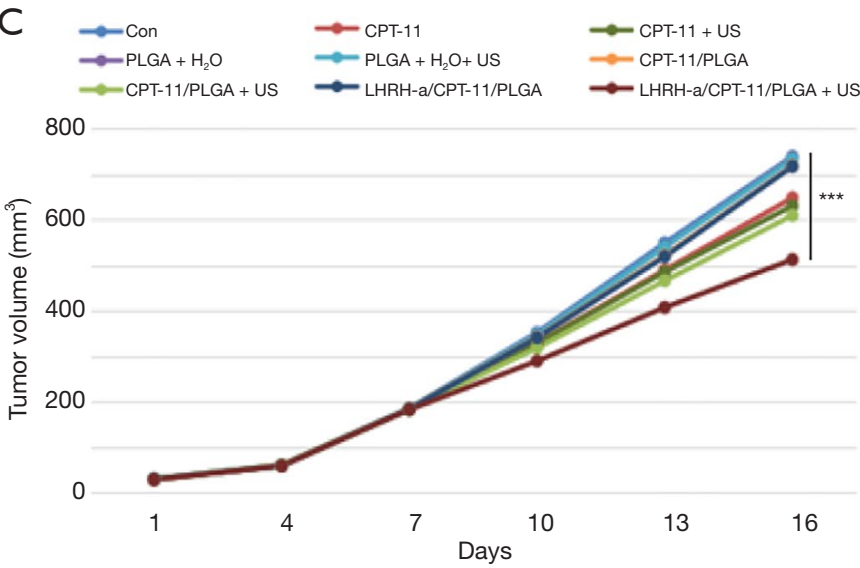

$\mathrm{D}$

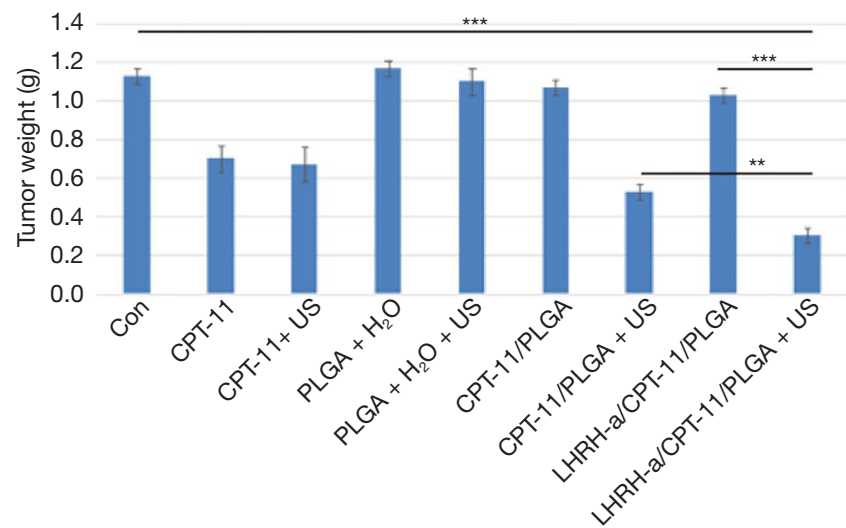

Figure 4 LHRH-a/CPT-11/PLGA nanoparticles targeted inhibit tumor growth. (A) Subcutaneous xenotransplantation tumor model of human ovarian tumor in nude mice. (B) LHRH-a/CPT-11/PLGA target xenograft tumor (×800). (C) Growth curve of transplanted tumor in nude mice of each treatment group. (D) Weight of transplanted tumor in each group after treatment. LHRH-a, luteinizing hormone releasing hormone analogue; CPT-11, irinotecan $\mathrm{HCl}$ trihydrate; PLGA, poly lactic-co-glycolic acid. ${ }^{* *}, \mathrm{P}<0.01$; ${ }^{* * *}, \mathrm{P}<0.001$.

obvious difference compared with controls group, which mean two groups of microspheres in the body were still stable, not easy to be destructed and to insourcing release chemotherapy drugs. PLGA- $\mathrm{H}_{2} \mathrm{O}$ group and PLGA- $\mathrm{H}_{2} \mathrm{O}$ with US group has no obvious statistical difference on the tumor inhibition, showed that low intensity ultrasound irradiation itself can't kill or inhibit tumor. This result was consistent with the research of $\mathrm{Pu}$ et al. (14). CPT-11/PLGA group and CPT-11/PLGA with US group, LHRH-a/ CPT-11/PLGA group and LHRH-a/CPT-11/PLGA with US group, they showed that PLGA micropellets can be broken by ultrasound under the stimulation of ultrasound localization and irradiation, and the CPT-11 chemotherapy drugs can be released under the action of ultrasound to play their role in inhibiting the growth of tumor tissue. CPT-11/ PLGA-US and LHRH-a/CPT-11/PLGA-US, these two groups of tumor growth inhibition rate also have obvious difference, because the targeted microspheres can bind with tumor, selectively gathered around the tumor tissues. Under the ultrasonic excitation, CPT-11 was released in the high local concentrations around the tumor tissue, inhibition was much higher. The LHRH-a/CPT-11/PLGA with US was also significantly different from that in the CPT-11 with US group, indicating that the targeted drug-carrying microspheres under the excitation of focused ultrasound could achieve significantly stronger inhibition of tumor tissue growth than the single drug treatment.

Vascular endothelial growth factor (VEGF) plays an important role in the invasion and metastasis of OC through binding to its corresponding receptor (VEGFR) $(14,15)$. With the increase of VEGF secretion, tumor angiogenesis contributes to the growth and metastasis of tumor cells. 


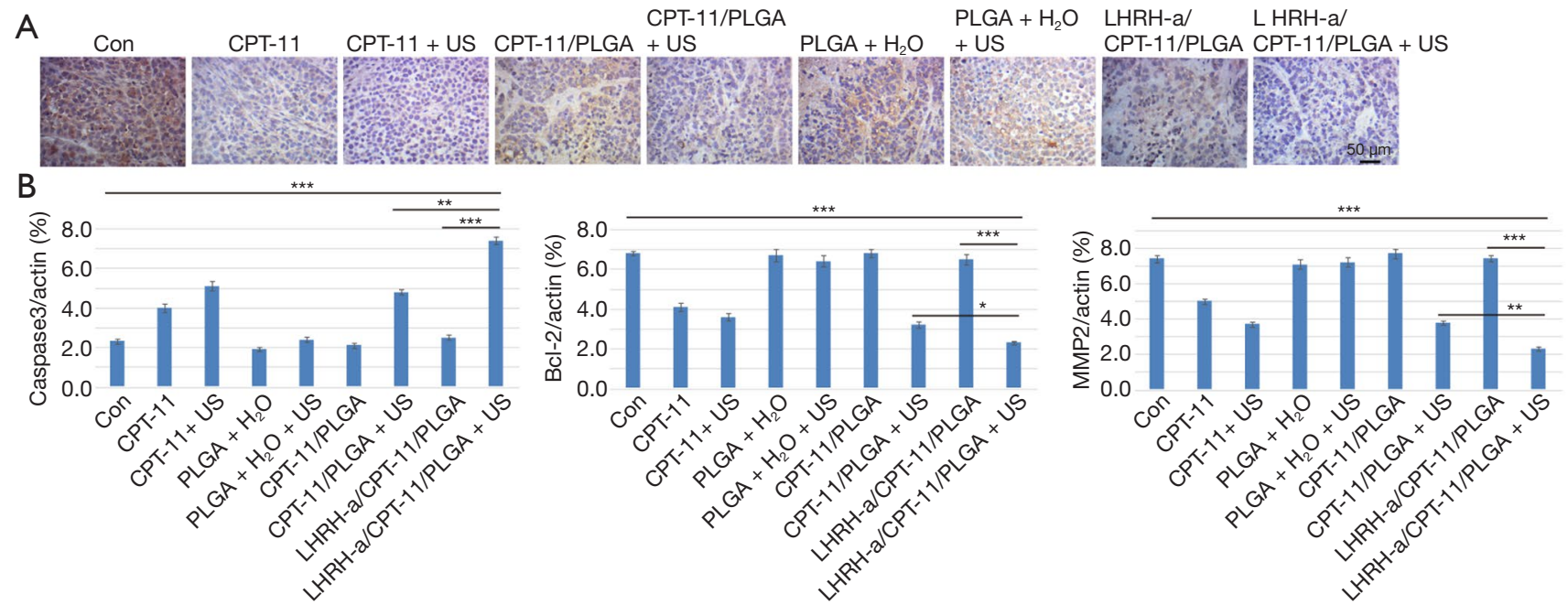

C
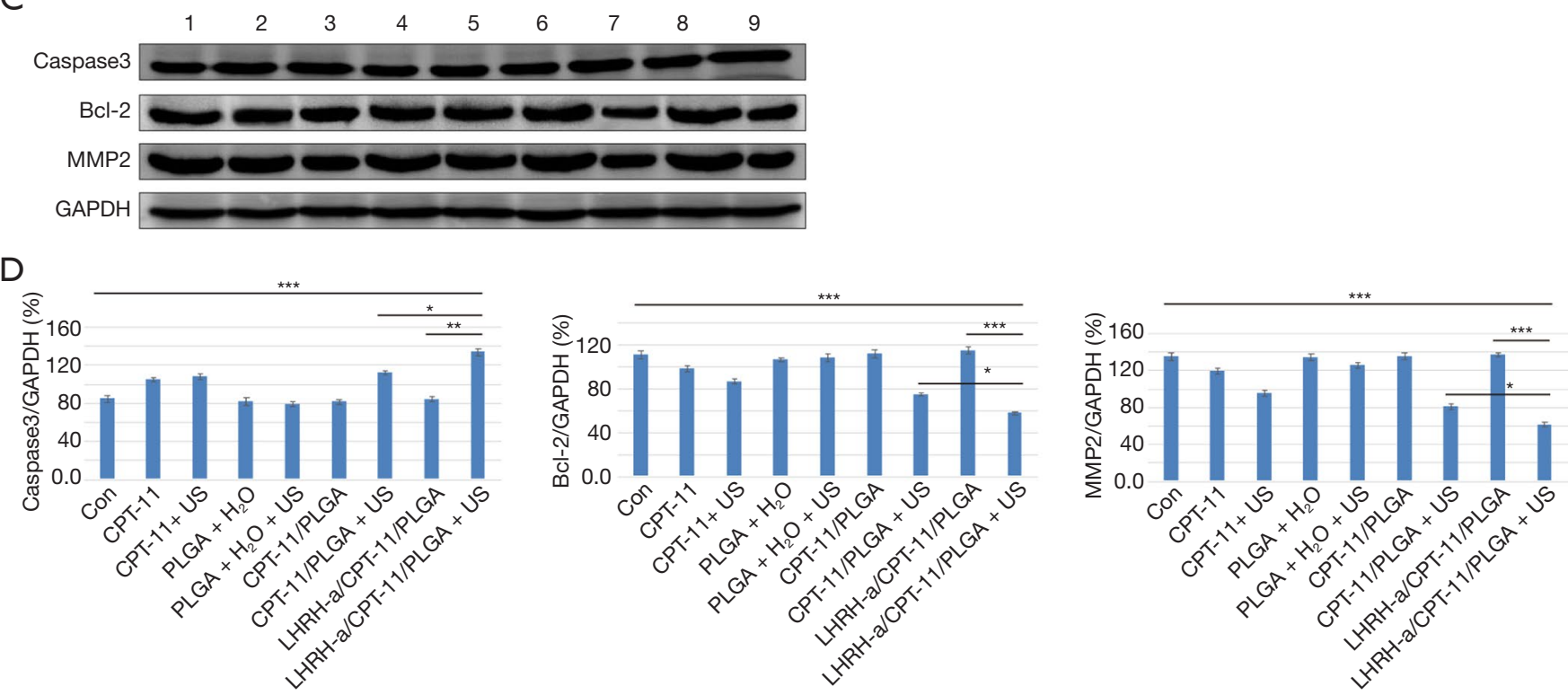

Figure 5 LHRH-a/CPT-11/PLGA nanoparticles promote tumor apoptosis. (A) VEGF expression level in transplanted tumor in each treatment group. (B) mRNA level of Bcl-2/caspase3, and MMP2 in tumor after treatment. (C,D) Protein level of Bcl-2/caspase3, and MMP2. In Figure 5C, 1, 2, 3, 4, 5, 6, 7, 8 and 9 represent Con, CPT-11, CPT-11 + US (focused ultrasound), PLGA + $\mathrm{H}_{2} \mathrm{O}, \mathrm{PLGA}+\mathrm{H}_{2} \mathrm{O}$ + US, CPT-11/PLGA, CPT-11/PLGA + US, LHRH- $\alpha /$ CPT-11/PLGA, LHRH- $\alpha /$ CPT-11/PLGA + US. LHRH-a, luteinizing hormone releasing hormone analogue; $\mathrm{CPT}-11$, irinotecan $\mathrm{HCl}$ trihydrate; $\mathrm{PLGA}$, poly lactic-co-glycolic acid. * $\mathrm{P}<0.05 ;{ }^{* *}, \mathrm{P}<0.01 ;{ }^{* * *}, \mathrm{P}<0.001$.

Immuno-histochemical results showed that the expression level of VEGF in the control group was the highest, and the expression level of VEGF in the PLGA- $\mathrm{H}_{2} \mathrm{O}$ group, PLGA- $\mathrm{H}_{2} \mathrm{O}$ with US group, CPT-11/PLGA group and LHRH-a/CPT-11/PLGA group was similar to the control group, followed by the CPT-11group, the CPT-11 with US group and the CPT-11/PLGA with US group, and the expression level in the LHRH-a/CPT-11/PLGA with US group was the lowest. As shown in Figure 5A, VEGF in the LHRH-a/CPT-11/PLGA with US treatment group was significantly lower than that in other treatment groups.

Meanwhile, we examined the expression of genes associated with apoptosis and invasion in OC cells. The results of real-time quantitative PCR showed that the mRNA expression levels of Bcl-2 and MMP2 in LHRH-a/ CPT-11/PLGA with US group were lower than other 
groups, while their mRNA expression levels of caspase-3 were significantly up-regulated. The mRNA expression of Bcl-2, Caspase3 and MMP2 in the LHRH-a/CPT-11/ PLGA with US group were significantly different from other treatment groups $(\mathrm{P}<0.01)$. CPT-11 group, CPT11 with US group and CPT-11/PLGA + US, compared with the control group, there was a significant difference $(\mathrm{P}<0.01)$. There were no significant differences between the PLGA- $\mathrm{H}_{2} \mathrm{O}$ group, the PLGA- $\mathrm{H}_{2} \mathrm{O}+\mathrm{US}$ group, the CPT11/PLGA group and the LHRH-a/CPT-11/PLGA group versus the control group $(\mathrm{P}>0.05)$, as shown in Figure $5 B$. Consistently, Western blotting analysis showed caspase3 in LHRH-a/CPT-11/PLGA + US group was significantly higher than other treatment groups $(\mathrm{P}<0.01)$, while $\mathrm{Bcl}-2$ and MMP2 expression in this group were significantly lower $(\mathrm{P}<0.05)$. As shown in Figure 5C,D, the expression of these protein markers in the CPT-11 group, CPT-11 with US group and CPT-11/PLGA + US group were significantly different compared with the control group $(\mathrm{P}<0.05)$, while there were no significant differences between the PLGA$\mathrm{H}_{2} \mathrm{O}$ group, PLGA- $\mathrm{H}_{2} \mathrm{O}$ with US group, CPT-11/PLGA group and LHRH-a/CPT-11/PLGA group versus control group $(\mathrm{P}>0.05)$.

The above results confirmed that targeted drugcarrying microspheres combined with focused ultrasound (LHRH-a/CPT-11/PLGA with US) can strongly inhibit the proliferation, invasion and metastasis of OC cells and drive apoptosis of OC cells.

\section{Discussion}

The survival of recurrent platinum resistant OC patients is short, and the treatment method is mainly palliative therapy. It is a challenge to improve the curative effect of the nonplatinum second-line chemotherapy drugs, and reduce the side effects of chemotherapy at the same time. Targeted delivery of drug-loaded microspheres is an effective method to solve this problem, and it is also a hot topic in the research of targeted therapy for tumor. It delivered drug along with the blood flow to the target tissue or organ, and the key steps include: ultrasonic localization irradiation, drug delivery microsphere rupture, drug release; an increase in drug concentration around targeting tumor, and exerting killing effects (16). In contrast, normal tissues (in nonultrasonic irradiation areas) are not affected and side effects can be largely avoided. Targeted nanospheres combined with focused ultrasound are expected to become a routine method for the treatment of malignant tumors (17).

At present, a large number of studies use lipid microspheres as drug carriers. However, these microspheres usually have a large particle size (most of which are more than $1,000 \mathrm{~mm}$ ). In addition, there are disadvantages such as low drug loading, poor stability and short drug maintenance time in target tissues and organs. In vivo, the lipid drug-carrying microspheres are easily affected by the complex internal environment in the body, such as temperature, shearing force of blood flow, etc. (18). The above shortcomings limit the wide application of lipid microspheres.

A large number of studies have shown that ultrasound assisted microspheres have better efficacy and lighter side effects than chemotherapy alone (19). The application of drug-loaded ultrasound microspheres in the treatment of OC has also been reported. Rapoport et al. first coated the chemotherapy drug paclitaxel with liposome microspheres and then administered the drug. Compared with the pure paclitaxel group, the drug efficacy of paclitaxel coated with liposomes was significantly enhanced, while the toxic and side effects related to paclitaxel were reduced by 10 times (20). Rapoport prepared a novel doxorubicin-carrying nanosphere by encapsulating doxorubicin with a polymer amine and adding perfluoropentane, which also had the function of ultrasonic imaging (21). Medda $\mathrm{et}$ al. prepared a targeted microsphere connected with LHRH-a and used it in the nude mouse OC A2780/DDP model. Similarly, it could enhance the apoptosis of tumor and inhibit tumor growth by affecting tumor angiogenesis. As a drug carrier, PLGA has obvious advantages over lipid microspheres including: small particle size, high drug loading, non-toxic side effects of biodegradable substances, good stability, etc. (22). The PLGA microsphere is more likely to pass through the vascular endothelial space to the tumor tissue space. Therefore, there are potential advantages in the treatment of recurrent platinum-resistant $\mathrm{OC}$ with ultrasonic nanoPLGA microsphere loaded with CPT-11 targeted delivery.

\section{Conclusions}

CPT-11 delivering PLGA nanoparticles with LHRH-a specifically target OC cell A2780/DDP, and work locally when combined with focused ultrasound. They increase local drug concentration and reduce side effects. This research may provide a new effective therapeutic strategy for recurrent platinum resistant ovarian cancer. 


\section{Acknowledgments}

The authors are grateful to Absatou Traoré, MAS, Department of Obstetrics and Gynecology, Third Xiangya Hospital, Central South University for her language editing assistance and contributions.

Funding: None.

\section{Footnote}

Reporting Checklist: The authors have completed the ARRIVE reporting checklist. Available at http://dx.doi. org/10.21037/tcr-20-3171

Data Sharing Statement: Available at http://dx.doi. org/10.21037/tcr-20-3171

Conflicts of Interest: All authors have completed the ICMJE uniform disclosure form (available at http://dx.doi. org/10.21037/tcr-20-3171). The authors have no conflicts of interest to declare.

Ethical Statement: The authors are accountable for all aspects of the work in ensuring that questions related to the accuracy or integrity of any part of the work are appropriately investigated and resolved. The study was conducted in accordance with the Declaration of Helsinki (as revised in 2013). Experiments were performed under a project license (license number: 2020SYDW0627) granted by the Veterinäramt des Kantons Zürich, Switzerland, in compliance with the Swiss Animal Protection Act (TSchG) and the Swiss Animal Protection Ordinance (TSchV).

Open Access Statement: This is an Open Access article distributed in accordance with the Creative Commons Attribution-NonCommercial-NoDerivs 4.0 International License (CC BY-NC-ND 4.0), which permits the noncommercial replication and distribution of the article with the strict proviso that no changes or edits are made and the original work is properly cited (including links to both the formal publication through the relevant DOI and the license). See: https://creativecommons.org/licenses/by-nc-nd/4.0/.

\section{References}

1. Yeung TL, Leung CS, Yip KP, et al. Cellular and molecular processes in ovarian cancer metastasis. A Review in the Theme: Cell and Molecular Processes in Cancer
Metastasis. Am J Physiol Cell Physiol 2015;309:C444-56.

2. Dobloug GC, Garen T, Brunborg C, et al. Survival and cancer risk in an unselected and complete Norwegian idiopathic inflammatory myopathy cohort. Semin Arthritis Rheum 2015;45:301-8.

3. Vargas-Hernandez VM, Moreno-Eutimio MA, AcostaAltamirano G, et al. Management of recurrent epithelial ovarian cancer. Gland Surg 2014;3:198-202.

4. Matsumoto K, Onda T, Yaegashi N. Pharmacotherapy for recurrent ovarian cancer: current status and future perspectives. Jpn J Clin Oncol 2015;45:408-10.

5. ten Bokkel Huinink W, Gore M, Carmichael J, et al. Topotecan versus paclitaxel for the treatment of recurrent epithelial ovarian cancer. J Clin Oncol 1997;15:2183-93.

6. Takeuchi S, Takamizawa H, Takeda Y, et al. An early phase II study of CPT-11 in gynecologic cancers. Research Group of CPT-11 in Gynecologic Cancers. Gan To Kagaku Ryoho 1991;18:579-84.

7. Melichar B, Hyspler R, Dragounova E, et al. Intestinal permeability and toxicity of second-line therapeutic agents in ovarian cancer. Tumori 2008;94:624-6.

8. Alimonti A, Gelibter A, Pavese I, et al. New approaches to prevent intestinal toxicity of irinotecan-based regimens. Cancer Treat Rev 2004;30:555-62.

9. Bodurka DC, Levenback C, Wolf JK, et al. Phase II trial of irinotecan in patients with metastatic epithelial ovarian cancer or peritoneal cancer. J Clin Oncol 2003;21:291-7.

10. Wei K. Future applications of contrast ultrasound. J Cardiovasc Ultrasound 2011;19:107-14.

11. He Y, Zhang L, Song C. Luteinizing hormone-releasing hormone receptor-mediated delivery of mitoxantrone using LHRH analogs modified with PEGylated liposomes. Int J Nanomedicine 2010;5:697-705.

12. Liu H, Chang S, Sun J, et al. Ultrasound-mediated destruction of LHRHa-targeted and paclitaxel-loaded lipid microbubbles induces proliferation inhibition and apoptosis in ovarian cancer cells. Mol Pharm 2014;11:40-8.

13. Torchilin V. Tumor delivery of macromolecular drugs based on the EPR effect. Adv Drug Deliv Rev 2011;63:131-5.

14. Pu C, Chang S, Sun J, et al. Ultrasound-mediated destruction of LHRHa-targeted and paclitaxel-loaded lipid microbubbles for the treatment of intraperitoneal ovarian cancer xenografts. Mol Pharm 2014;11:49-58.

15. Ueda M, Terai $Y$, Kumagai K, et al. Vascular endothelial growth factor $\mathrm{C}$ gene expression is closely related to invasion phenotype in gynecological tumor cells. Gynecol 
Oncol 2001;82:162-6.

16. Ellegala DB, Leong-Poi H, Carpenter JE, et al. Imaging tumor angiogenesis with contrast ultrasound and microbubbles targeted to alpha(v)beta3. Circulation 2003;108:336-41.

17. Willmann JK, Kimura RH, Deshpande N, et al. Targeted contrast-enhanced ultrasound imaging of tumor angiogenesis with contrast microbubbles conjugated to integrin-binding knottin peptides. J Nucl Med 2010;51:433-40.

18. Ting CY, Fan CH, Liu HL, et al. Concurrent bloodbrain barrier opening and local drug delivery using drugcarrying microbubbles and focused ultrasound for brain glioma treatment. Biomaterials 2012;33:704-12.

Cite this article as: Zhu X, Yan S, Xiao F, Xue M. PLGA nanoparticles delivering CPT-11 combined with focused ultrasound inhibit platinum resistant ovarian cancer. Transl Cancer Res 2021;10(4):1732-1743. doi: 10.21037/tcr-20-3171
19. Shen YY, Gao ZG, Rapoport N. Recent advances in the applications of ultrasonic microbubbles as gene or drug vectors. Yao Xue Xue Bao 2009;44:961-6.

20. Unger EC, McCreery TP, Sweitzer RH, et al. Acoustically active lipospheres containing paclitaxel: a new therapeutic ultrasound contrast agent. Invest Radiol 1998;33:886-92.

21. Rapoport N, Gao Z, Kennedy A. Multifunctional nanoparticles for combining ultrasonic tumor imaging and targeted chemotherapy. J Natl Cancer Inst 2007;99:1095-106.

22. Medda S, Jaisankar P, Mannah RK, et al. Phospholipid microspheres: A novel delivery mode for targeting antileishmanial agent in experimental leishmaniasis. J Drug Target 2003;11:123-8. 